\title{
Impact of tropical SST variations on the linear predictability of the atmospheric circulation in the Atlantic/European region
}

\author{
Henrik Feddersen \\ Climate Research Division, Danish Meteorological Institute, Copenhagen, Denmark
}

\begin{abstract}
Seasonal mean values of tropical Sea Surface Temperature (SST) and Atlantic/European Mean Sea Level Pressure (MSLP) from a 301-year coupled ocean/atmosphere model run are analysed statistically. Relations between the two fields are identified on both interannual and interdecadal timescales. It is shown that tropical SST variability affects Atlantic/European MSLP in winter. In particular, there appears to be a statistically significant relation between the leading modes of variability, the El Niño/Southern Oscillation (ENSO) and the North Atlantic Oscillation (NAO). During cold ENSO (La Niña) years the NAO tends to be in its positive phase, while the opposite is the case during warm ENSO (El Niño) years, although to a lesser extent. Similar analyses that are presented for gridded observational data, confirm this result, although here tropical Atlantic SST appears to be stronger related to the NAO than tropical Pacific SST. The linear predictability of a model simulated NAO index is estimated by making statistical predictions that are based on model simulated tropical SST. It is shown that the predictive skill is rather insensitive to the length of the training period. On the other hand, the skill score estimate can vary significantly as a result of interdecadal variability in the climate system. These results are important to bear in mind when making statistical seasonal forecasts that are based on observed SST.
\end{abstract}

Key words seasonal predictability - statistical analysis - ENSO - NAO

\section{Introduction}

Interannual variability of the large-scale atmospheric circulation in the Atlantic/European region is dominated by variability that is internal to the atmosphere. The internal variability is largely a result of the chaotic dynamics of the at-

Mailing address: Dr. Henrik Feddersen, Climate Research Division, Danish Meteorological Institute, Lyngbyvej 100, DK-2100 Copenhagen Ø, Denmark e-mail: hf@dmi.dk mosphere in the Atlantic/European region, and thus the potential would seem limited for seasonal to interannual prediction of European climate (Rowell, 1998). However, both observational and model studies suggest that a small fraction of the Atlantic/European interannual climate variability is affected by the tropical oscillations through atmospheric teleconnections. Several analyses of interannual variability in general circulation models (Brankovic and Palmer, 1997; Davies et al., 1997; May and Bengtsson, 1998; Feddersen, 2000) as well as analyses of observational data (Fraedrich and Müller, 1992; Pozo-Vazquez et al., 2001) have demonstrated a link between the El Niño/ Southern Oscillation (ENSO) and the winter climate in Europe, including the seasonal mean 
phase of the North Atlantic Oscillation (NAO). In summary, these papers find that cold ENSO events are associated with the positive phase of the NAO, while warm ENSO events (to a lesser extent) are associated with the negative phase of the NAO.

The identified statistical links between ENSO events and the phase of the NAO hold some potential for Atlantic/European seasonal to interannual predictability, particularly in years with large tropical Sea Surface Temperature (SST) anomalies, although a study by Johansson et al. (1998) found no significant predictability of surface air temperature in Northern Europe associated with ENSO. It is possible that in this study no predictability was detected because the region that was considered, is rather small, and the study was based on a relatively short period (39 years) which may not be long enough to identify a teleconnection signal that is hidden in the chaotic internal variability. Thus, there is a need for longer time series of data.

Given the lack of observational data back in time, we focus our analysis in the present study on data time series from a 301-year integration of the ECHO-G coupled ocean/atmosphere general circulation model. Such long time series allow us not only to better identify tropical/ extratropical teleconnection signals, but also to study the robustness over many decades of the teleconnection relations. Comparisons with analyses of observational data are made when the observational data series are sufficiently long to do so.

Teleconnections on interdecadal timescales are also identified between tropical SST and atmospheric variability in the Atlantic/European region in the model time series. Teleconnections on these longer timescales will show up in interannual climatic time series as apparent trends, and they also contribute (positively or negatively) to the interannual predictability.

The paper is organised as follows. The analysed observational data and the 301-year model run are briefly described in Section 2. Section 3 describes teleconnections between tropical SST and Atlantic/European Mean Sea Level Pressure (MSLP), both for observations (for the period 1903-94) and for the 301-year model run. Here and in the following we consider only the January-March (JFM) season. The teleconnection patterns are identified by applying a Singular Value Decomposition (SVD) analysis to cross-covariances of tropical SST and Atlantic/ European MSLP in JFM. In Section 4 a similar SVD analysis is applied to JFM time series that are averaged over several years in order to study teleconnections that relate to interdecadal variability. Section 5 discusses implications for the interannual predictability of Atlantic/ European MSLP. In particular, data from the model run is used as synthetic data for statistical predictions of a NAO index and European surface temperatures in winter. The relatively long model run allows us to discuss aspects of the robustness of statistical predictions which is not possible for the much shorter observational data series. Finally, conclusions are presented in Section 6.

\section{Data}

\subsection{Observational data}

Globally gridded observations of tropical SST have been taken from the GISST2.2 dataset which includes monthly mean values for the 1903-1994 period on a $1^{\circ} \times 1^{\circ}$ grid (Rayner et al., 1996). However, here we include only every third grid box in both directions in order to obtain a resolution comparable to the model's T30 resolution.

The MSLP data was taken from a $5^{\circ} \times 10^{\circ}$ gridded dataset from the Climatic Research Unit. This dataset covers the Northern Hemisphere from $15^{\circ} \mathrm{N}-85^{\circ} \mathrm{N}$ and includes monthly mean values for the 1873-1995 period (Jones, 1987; Basnett and Parker, 1997).

\subsection{Model data}

We use seasonally averaged data from a 301year simulation of the present-day climate from the ECHO-G coupled ocean/atmosphere general circulation model. The model consists of the ECHAM4 atmospheric model (e.g., Roeckner et al., 1996; Stendel and Roeckner, 1998) and the HOPE-G ocean model, including a dynamic/ 
thermodynamic sea ice model (e.g., Legutke and MaierReimer, 1999). ECHAM4 has a horizontal resolution of T30 (corresponding to $48 \times 96$ grid points on the corresponding Gaussian grid) and 19 vertical levels (e.g., Stendel and Roeckner, 1998). In the extratropics HOPE-G has a horizontal resolution of $2.8125^{\circ}$, corresponding to a triangular truncation of T42. In a band from $30^{\circ}$ to $10^{\circ}$ off the equator the distance between latitudes decreases to $0.5^{\circ}$ in order to better resolve the equatorial dynamics. The vertical resolution of HOPE-G is 20 layers.

\section{Interannual covariability}

\subsection{Observational data}

An SVD analysis (Bretherton et al., 1992; Wallace et al., 1992) was applied to JFM seasonal means of 92 years (1903-94) of gridded observations of tropical SST and Atlantic/European MSLP. Both the SST and MSLP fields were standardised prior to the SVD analysis so that all grid boxes contribute the same amount to the analysis.

The SVD analysis can in many respects be regarded as an extension of the well-known principal component (or EOF) analysis. In the latter, one or more patterns are derived that maximise the fraction of «explained» variance for a particular field, whereas the SVD analysis provides one or more pairs of patterns that maximise the fraction of «explained» covariance between two fields. It is common practice to give the Squared Covariance Fraction (SCF) that is associated with a pair of SVD patterns, just like it is common practice to always give the fraction of explained variance that is associated with an EOF pattern. Both the SCF and the correlation between the associated SVD time series are often found to be very high for the leading SVD mode. However, this does not necessarily imply a strong statistical connection between the two fields (Wallace et al., 1992; Cherry, 1996). Therefore, additional tests of statistical significance are required.

Here we use a Monte Carlo resampling to test statistical significance (Ward and Navarra, 1997). The Atlantic/European MSLP time series are randomly resampled 200 times, and each time an SVD analysis is applied to tropical SST and the resampled MSLP. An estimate of the significance level (i.e. the probability that an equally strong coupled mode would appear by chance for independent SST and MSLP fields) is then given by the number of times that the randomly generated SCF exceeds the actual SCF divided by the total number of times the SVD analysis was applied to the resampled MSLP fields and tropical SST. In order for the resampled time series to appear random, the original MSLP time series must not be serially correlated. It was checked that serial correlation is not a problem.

Figure 1a,b shows the leading pair of heterogeneous correlation patterns, i.e. the temporal correlation in each grid box between the standardised time series of one field (MSLP in fig. 1a; SST in fig. 1b) and the first SVD time series of the opposite field (Bretherton et al., 1992). Thus, the heterogeneous correlation pattern for MSLP shows how well MSLP anomalies can be specified from the first SVD time series of tropical SST, i.e. the heterogeneous correlation pattern yields an estimate of the skill of SVD predictions of Atlantic/European MSLP if the predictions were based on the statistical link between tropical SST and Atlantic/European MSLP. The total interannual MSLP variance that is «explained» by tropical SST is simply given by the area average of the squared correlations in fig. 1a. The first pair of SVD time series for Atlantic/European MSLP and tropical SST, respectively, are shown in fig. 2a,b.

The MSLP pattern shows a north/south dipole which is also found in the first EOF of JFM MSLP (fig. 3, the NAO pattern in its negative phase), but in the EOF pattern the dipole is much more pronounced over the European continent than what is seen in fig. 1a. Likewise, the tropical SST pattern bears some resemblance to the first EOF of tropical JFM SST (not shown). But the SST pattern in fig. $1 \mathrm{~b}$ has relatively more weight in the tropical Atlantic, while the first EOF looks more like the generic ENSO pattern of Harrison and Larkin (1998). The SVD patterns are found to be statistically significant at a 3.5\% level, using the Monte Carlo resampling test, so the SVD analysis supports the notion that warm (cold) tropical SST is associated with an atmospheric 
(a)

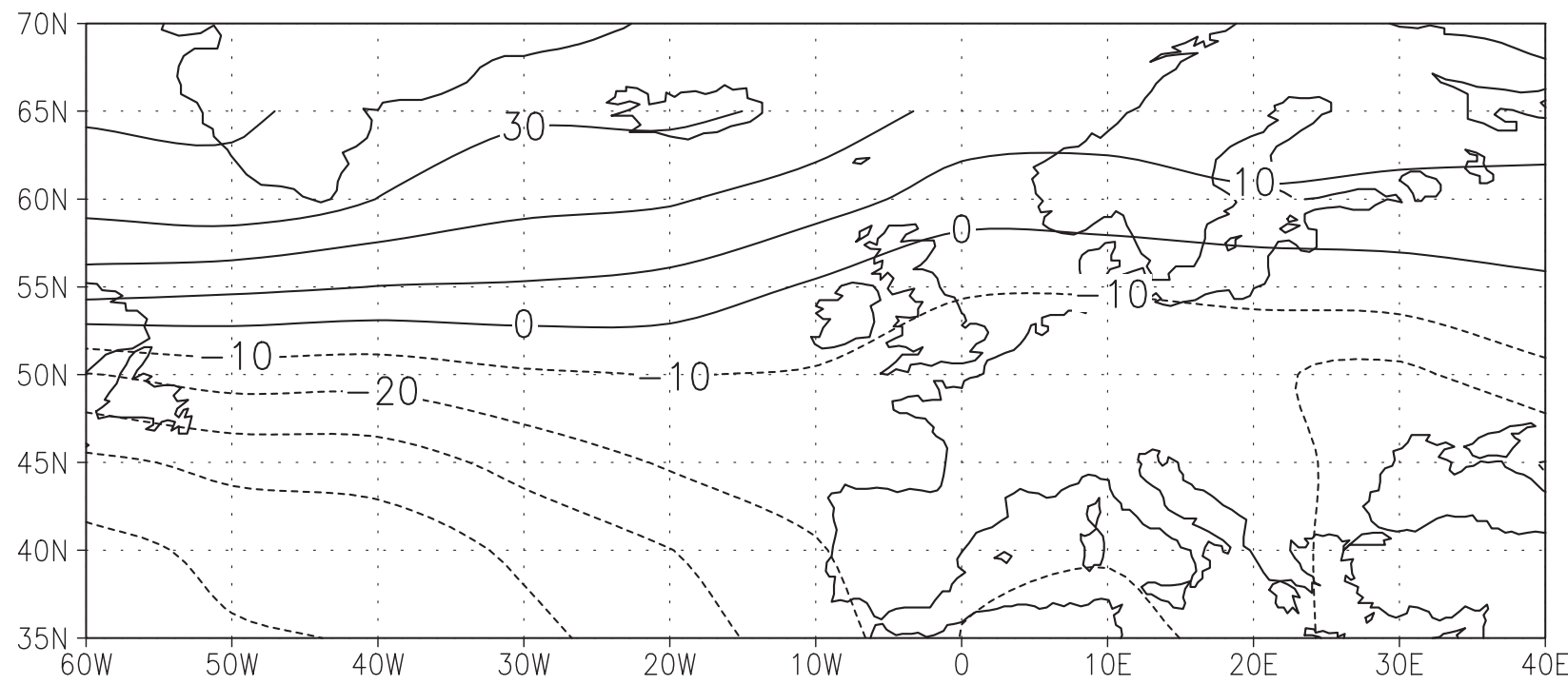

(b)

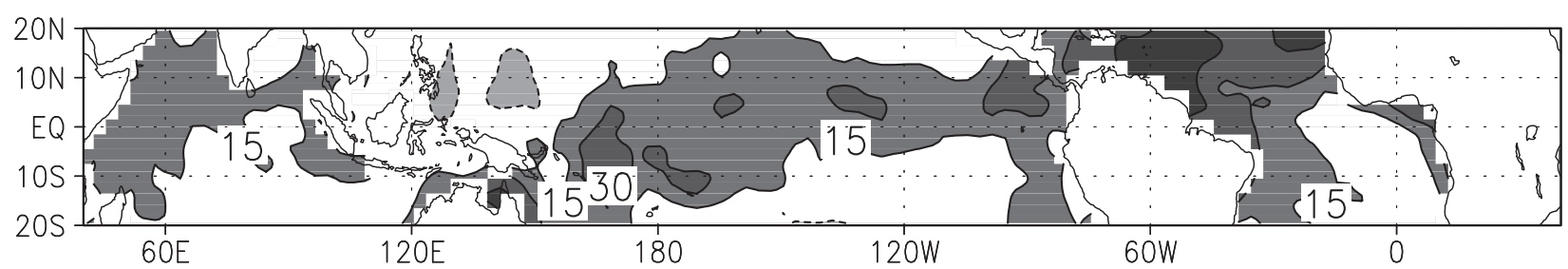

Fig. 1a,b. Leading pair of heterogeneous correlation patterns from an SVD analysis of 92 years (1903-1994) of gridded observations of JFM seasonal mean tropical SST and JFM seasonal mean Atlantic/European MSLP. a) MSLP correlations (in \%); b) SST correlations (in \%). Squared covariance fraction $=73 \%$. Total explained MSLP variance fraction in Atlantic/European region $=7 \%$. Statistical significance level $=3.5 \%$.
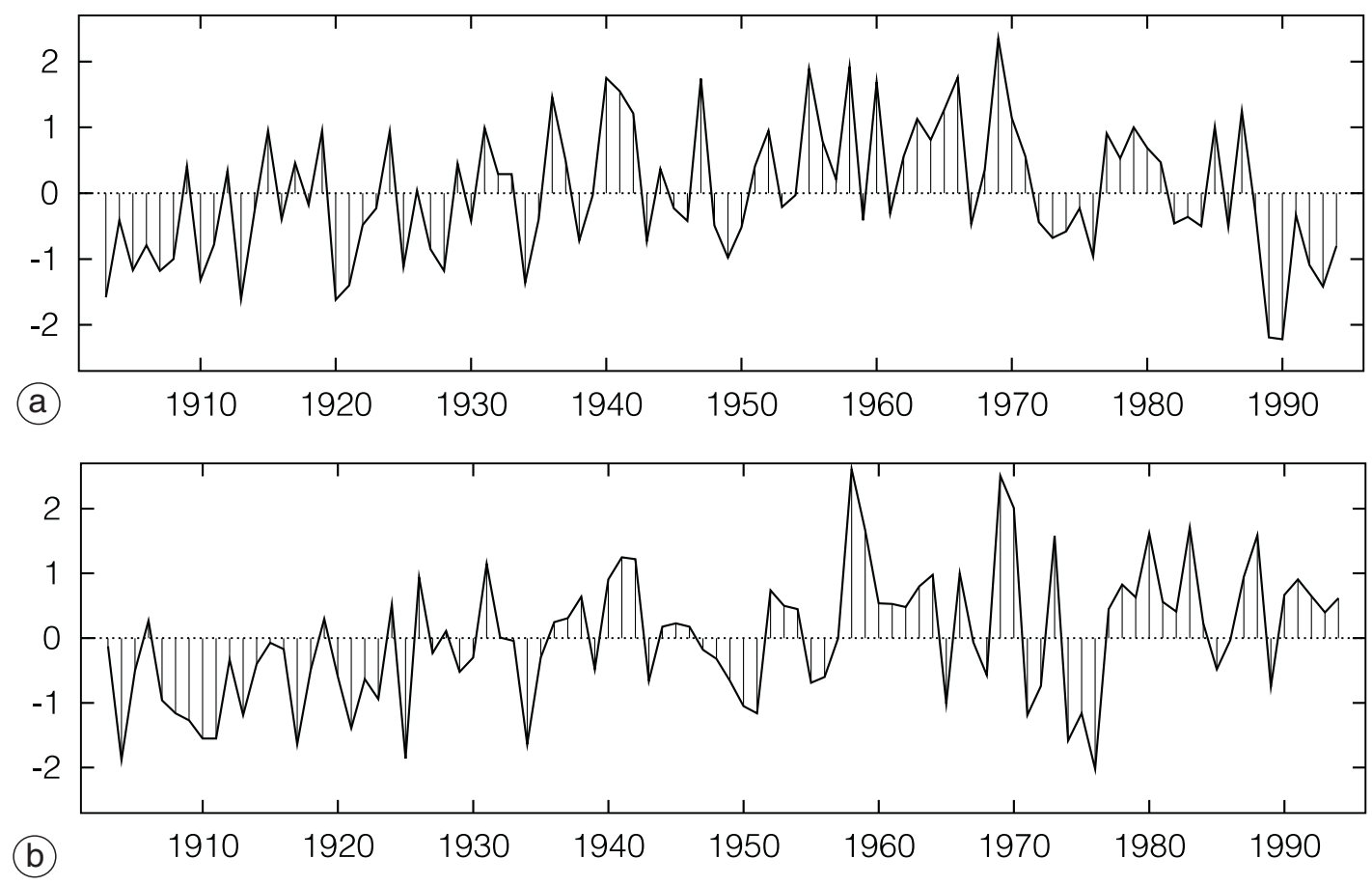

Fig. 2a,b. Standardised time series for the patterns in fig. 1a,b. a) For Atlantic/European MSLP; b) for tropical SST. Correlation coefficient between time series is 0.44 . 


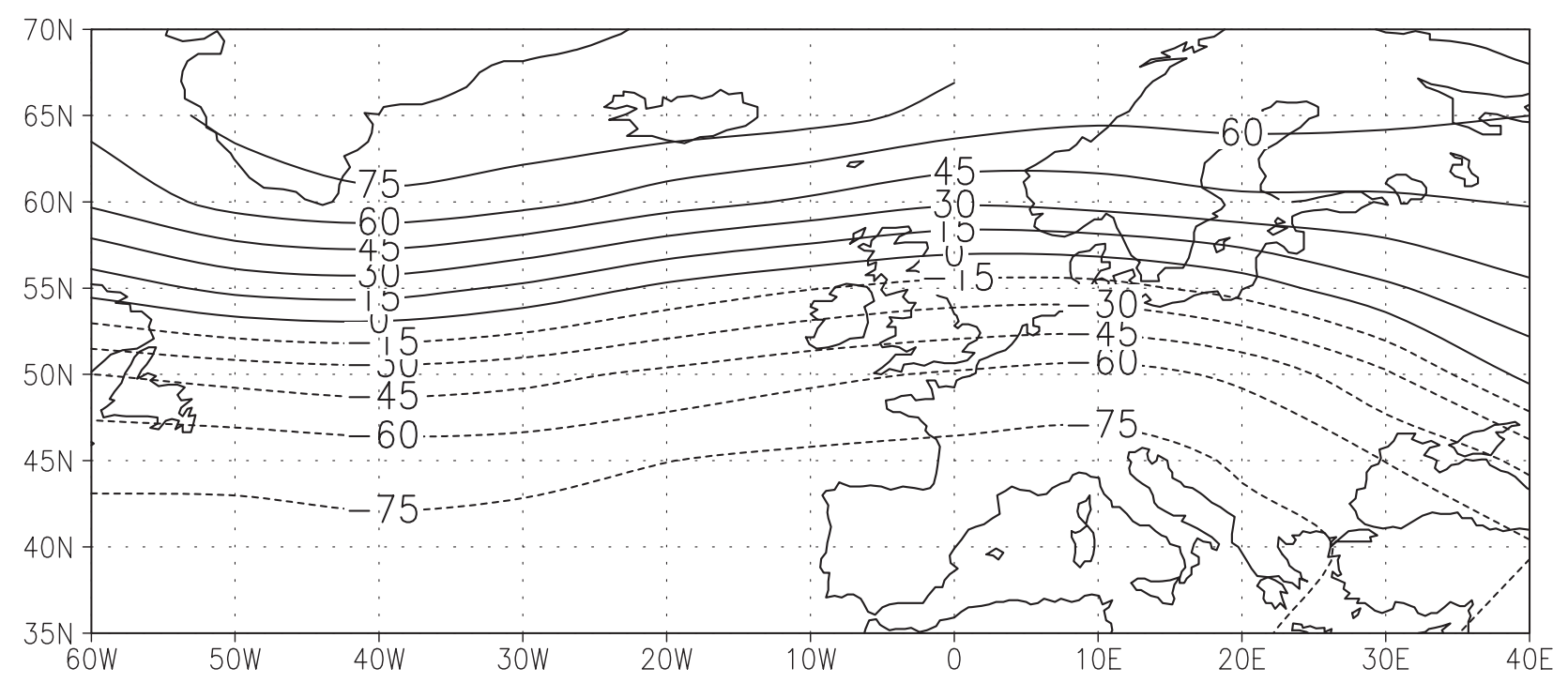

Fig. 3. First EOF pattern (explaining $43 \%$ of the total variance) of gridded observations of JFM seasonal mean Atlantic/European MSLP.

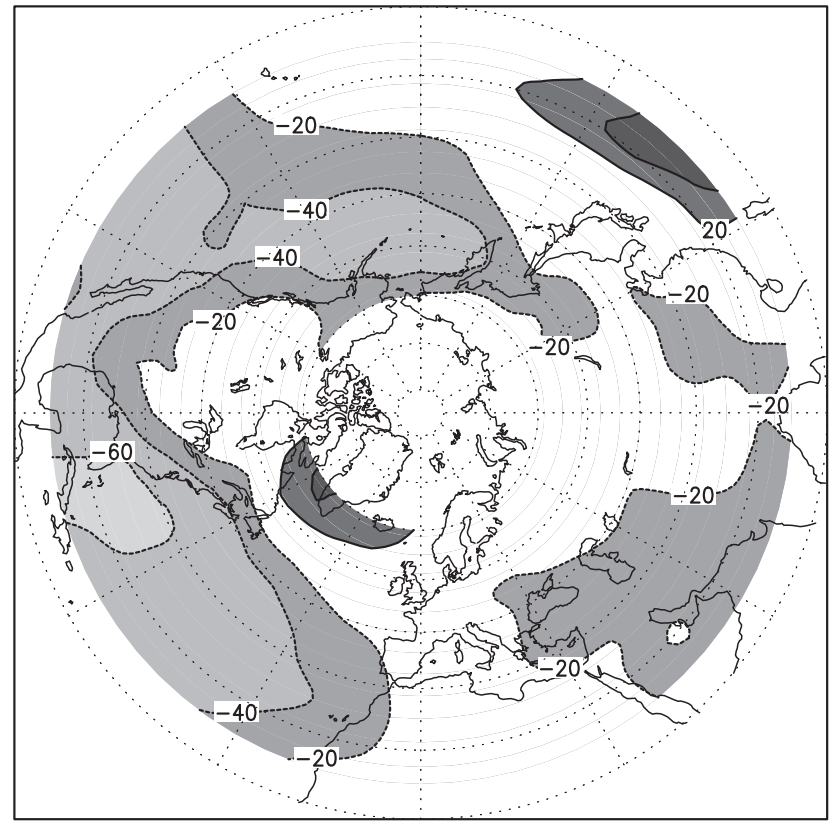

Fig. 4. Correlations (in \%) between the tropical SST time series (fig. 2b) and gridded observations of MSLP on the Northern Hemisphere north of $15^{\circ} \mathrm{N}$.

large-scale circulation in winter over the Atlantic/ European region that more or less corresponds to the negative (positive) phase of the NAO. The MSLP pattern, however, only explains about $7 \%$ of the total variance, so the impact of tropical
SST is likely to be felt in the Atlantic/European region only in years of extreme tropical SST anomalies.

If the SVD time series for tropical SST is correlated with the MSLP time series in each grid box in the Northern Hemisphere then the pattern in fig. 4 is obtained. This pattern shows that the Atlantic/European MSLP pattern is just a weak part of an hemispheric pattern which has a strong centre of action over the tropical Atlantic and a secondary centre over the western part of the tropical Pacific.

\subsection{Model data}

A similar SVD analysis was applied to the 301-year of model simulated JFM seasonal mean tropical SST and JFM seasonal mean Atlantic/ European MSLP. The first pair of heterogeneous correlation patterns are shown in fig. 5a,b. The Pacific part of the SST pattern is dominating the pattern and is similar to the model's ENSO pattern (calculated as the first EOF of tropical Pacific SST; not shown). Likewise, the MSLP pattern in the Atlantic/European region bears some resemblance to the first model EOF pattern (fig. 6, NAO pattern in its negative phase). However, the model's first EOF pattern is located 


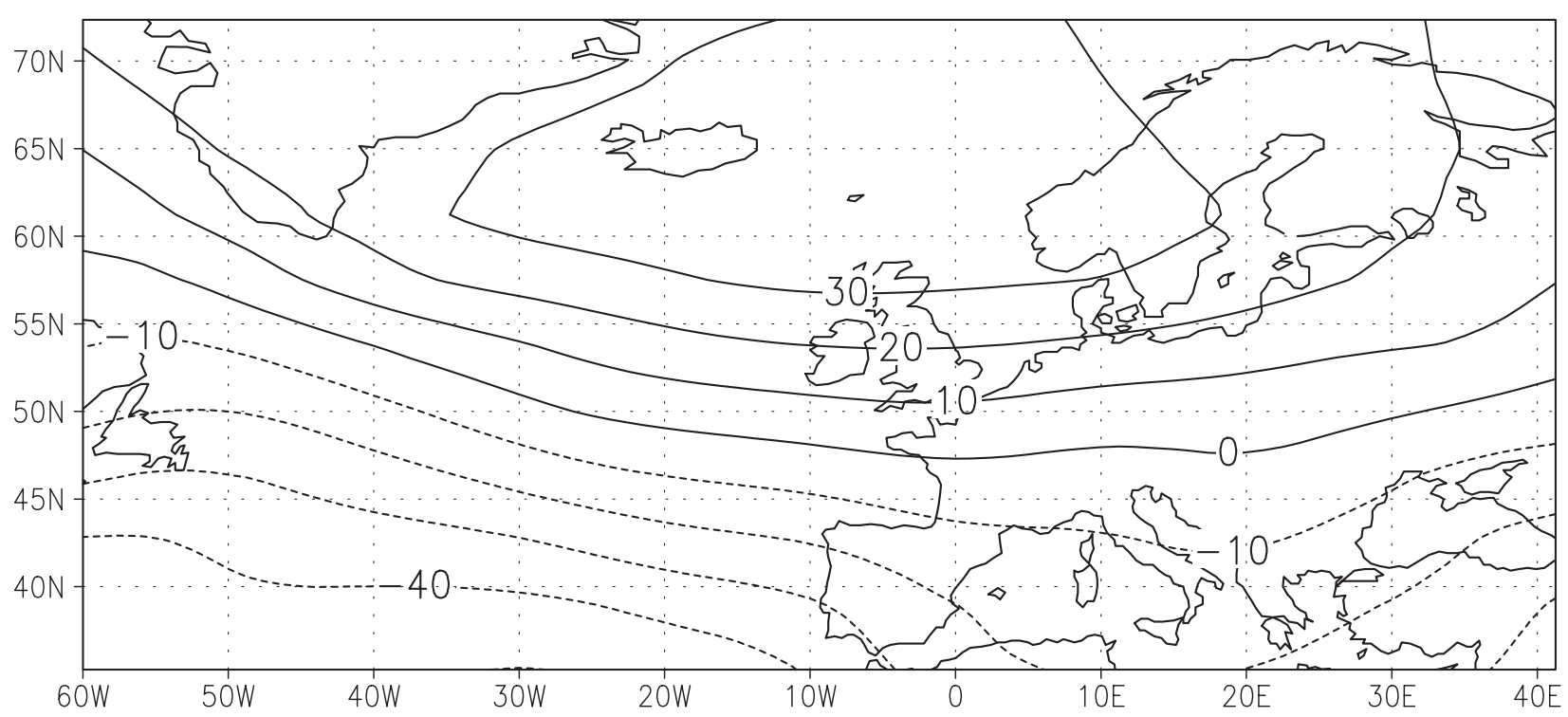

(a)

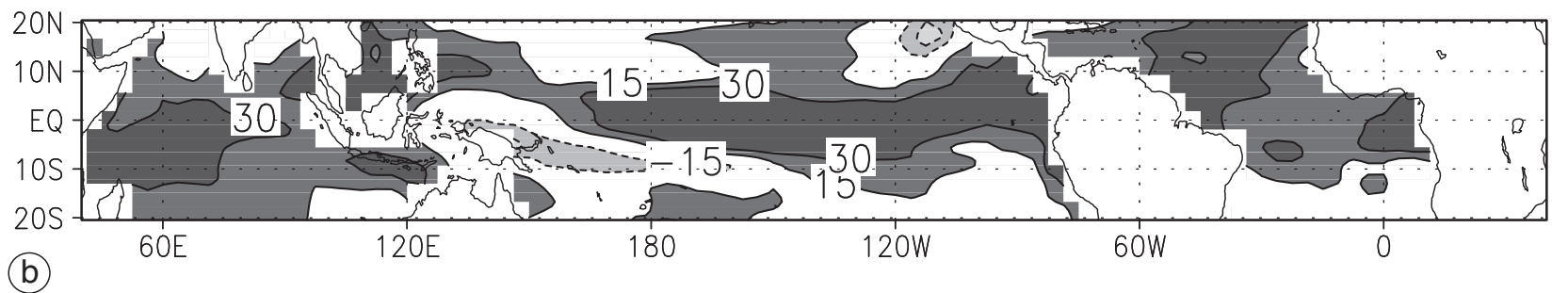

Fig. 5a,b. Leading pair of heterogeneous correlation patterns from an SVD analysis of 301 years of model simulated JFM seasonal mean tropical SST and JFM seasonal mean Atlantic/European MSLP. a) MSLP correlations (in \%); b) SST correlations (in \%). Squared covariance fraction $=84 \%$. Total explained MSLP variance fraction in Atlantic/European region $=7 \%$. Statistical significance level $<0.5 \%$.

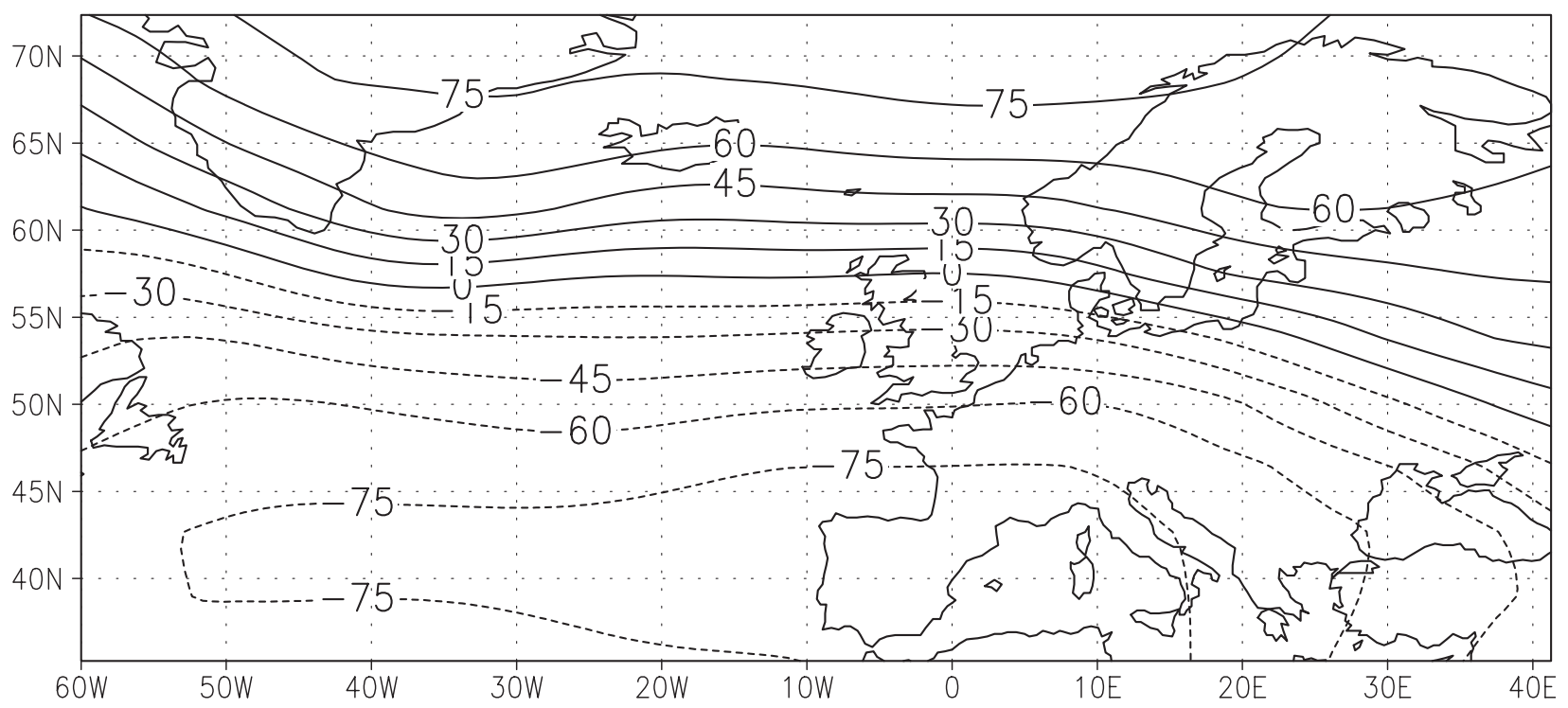

Fig. 6. First EOF pattern (explaining $38 \%$ of the total variance) of model simulated JFM seasonal mean Atlantic/ European MSLP. 
slightly north of the SVD pattern, and over the Iberian peninsula the EOF pattern has a centre which is absent in the SVD pattern, while the EOF pattern does not show the centre north of Scotland. Nevertheless, the SVD analysis of the model run supports the observational finding that tropical SST modulates the NAO so that a negatively phased NAO is more likely in winters with warm tropical SST anomalies, whereas a positively phased NAO is more likely in winters with cold tropical SST anomalies. The first SVD pattern is found to be highly statistically significant (with an estimated significance level < $0.5 \%$ ), although the Atlantic/European MSLP pattern explains only $7 \%$ of the total interannual variance for the JFM season. If we consider only the years when the tropical SST is most extreme, then the fraction of MSLP variance explained by tropical SST is considerably higher. For example, for the years of the 25 most positive values and
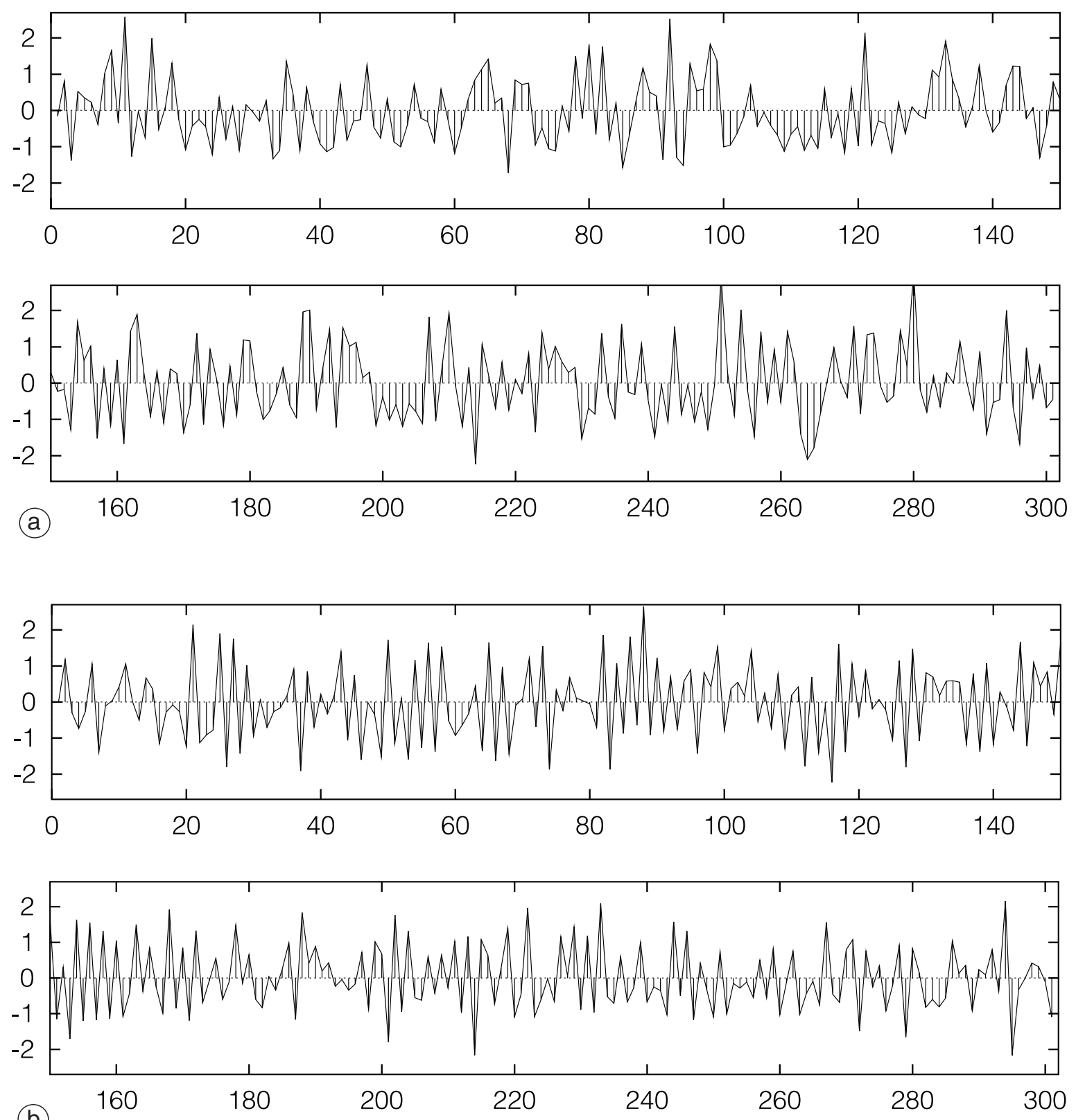

Fig. 7a,b. Standardised time series for the patterns in fig. 5a,b. a) For Atlantic/European MSLP; b) for tropical SST. Correlation coefficient between time series is 0.45 . 
the 25 most negative values of the SVD time series for SST we find that tropical SST explains about $16 \%$ of the corresponding MSLP variance.

The associated standardised time series are shown in fig. 7a,b. The SST time series has a very strong biennial component which is not seen in the observations ( $c f$. fig. 2a,b). This biennial component reflects the model's tendency to switch back and forth between El Niño and La Niña states almost every year. This tendency is not seen in the MSLP time series. In fact, the autocorrelation function for the MSLP time series is similar to that of white noise (not shown), but although the MSLP variations appear as those of a random process, the correlation coefficient between the MSLP and the SST time series is 0.45 , so the MSLP is not statistically independent of the tropical SST variations.

The pattern of correlations between the SVD time series for tropical SST and the time series for MSLP in each grid box in the Northern Hemisphere is shown in fig. 8. The strongest correlations are found over the tropical Pacific, indicating that ENSO is the dominant source of the variability in the tropical Pacific that influences Atlantic/European MSLP variability.

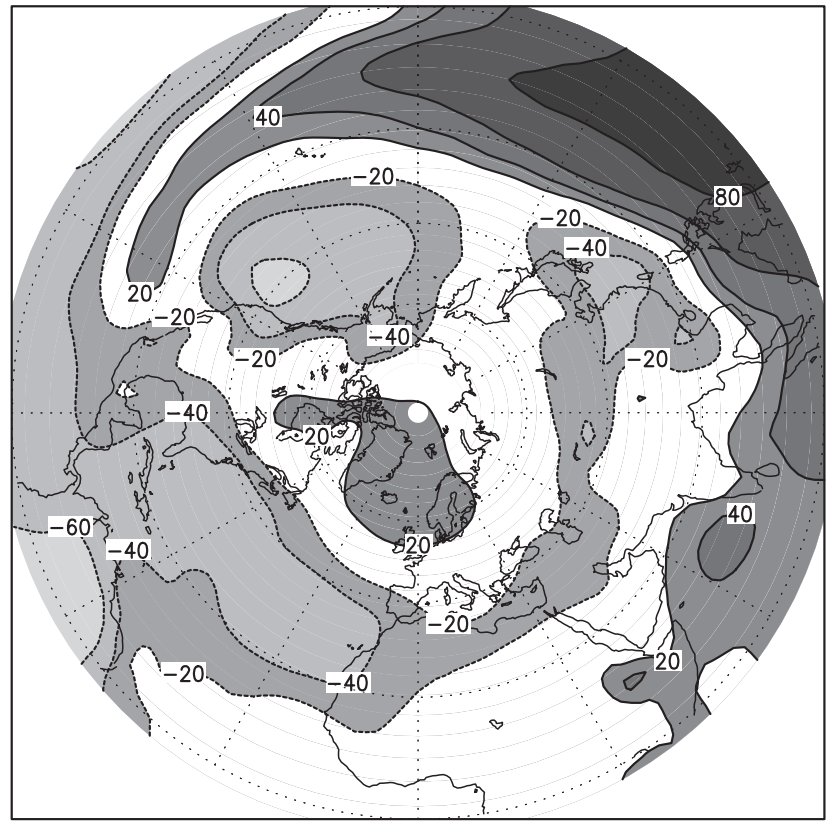

Fig. 8. Correlations (in \%) between the tropical SST time series (fig. 7b) and model simulated MSLP on the Northern Hemisphere.
Notice that north of the direct influence of the southern oscillation, the pattern has some resemblance with the surface part of the Arctic oscillation pattern (Thompson and Wallace, 1998).

It appears that in the model's climate tropical Pacific SST is the most important part of the tropical SST in relation to the Atlantic/European MSLP variability, and, indeed, if the SVD analysis is repeated with tropical Pacific SST only, then an almost identical MSLP pattern and almost identical SVD time series are recovered (not shown). But, interestingly, this is also the case if the SVD analysis is repeated with tropical Atlantic SST only. So the notion of one dominant tropical oscillation (which itself is dominated by ENSO) seems reasonable in this coupled ocean/ atmosphere model.

The SVD analysis gives no indication of cause and effect, but it seems most likely that the tropical SST has a (small) influence on Atlantic/European interannual MSLP variability and not vice versa. This assumption is confirmed by applying an SVD analysis to tropical SST in the OND season and Atlantic/European MSLP in the following JFM season. The resulting leading pair of heterogeneous correlation patterns (not shown) are very similar to the pair of no-lag patterns in fig. 5a,b, except that the correlations generally are lower in the lagged patterns.

\section{Interdecadal covariability}

In order to study teleconnections that relate to interdecadal variability - loosely defined as variations with periods between 10 and 100 years new time series are constructed by dividing the original long model time series into 5-year chunks, each one of which is represented by an average value. Note that we are not using running means; there is no overlap between two 5-year chunks. Thus, for the 301-year model simulation the new «decadal» time series can have a length of 60 at most. The period of five years is chosen because it represents the minimal sampling frequency that is needed in order to resolve 10year periods, and also because 5-year averages are long enough to eliminate effects of the strong biennial ENSO variation. 
An SVD analysis similar to the ones described in the previous section was applied to the decadal time series of model simulated tropical SST and model simulated Atlantic/
European MSLP, but the Monte Carlo resampling test for statistical significance gave a significance level $>20 \%$, i.e. no statistical significance. However, if SST leads MSLP by one year (i.e.

(a)
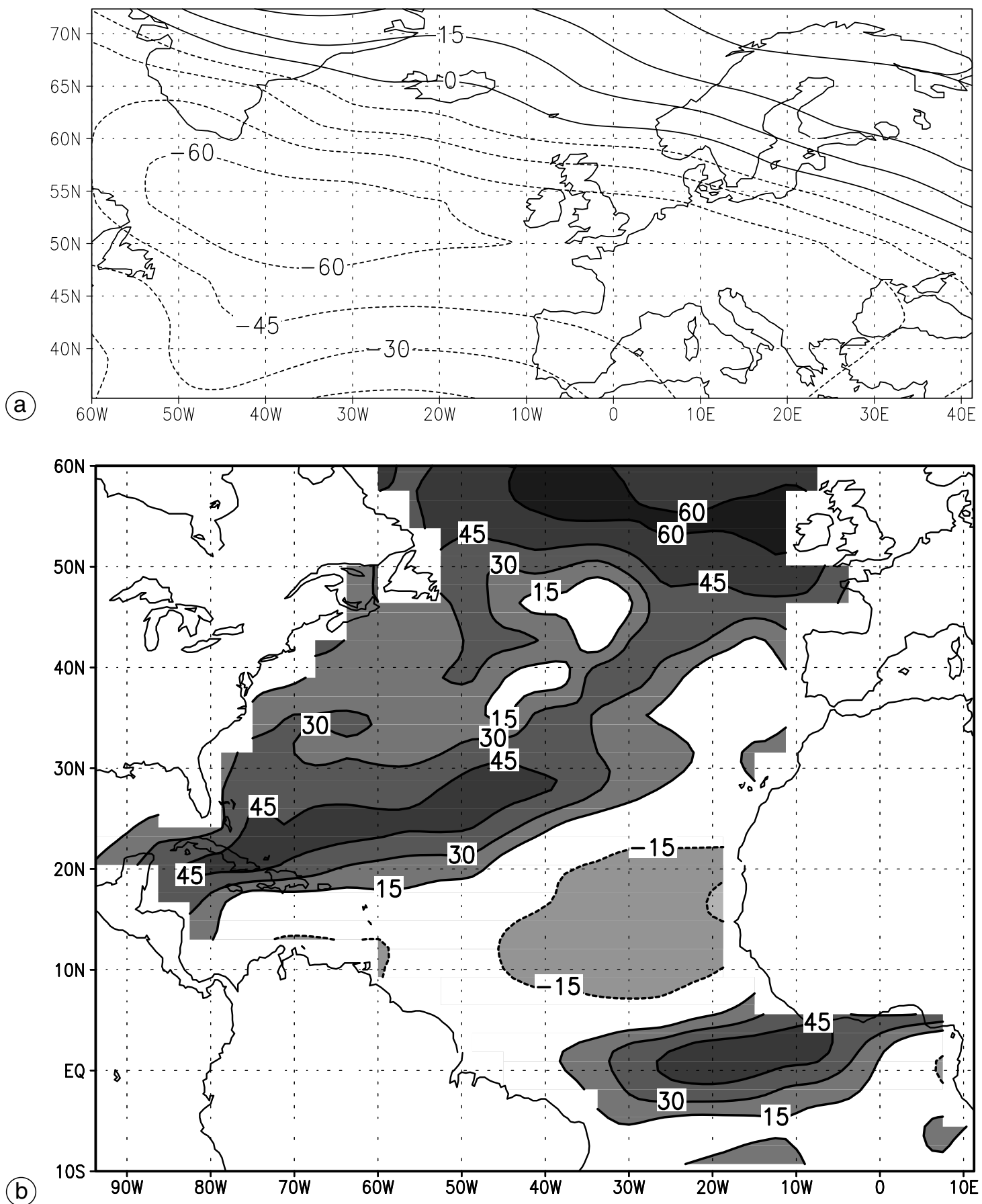

Fig. 9a,b. Leading pair of heterogeneous correlation patterns from an SVD analysis of 605 -year averages of model simulated JFM seasonal mean Atlantic SST and JFM seasonal mean Atlantic/European MSLP. SST leads MSLP by one year as described in text. a) MSLP correlations (in \%); b) SST correlation (in \%). Squared covariance fraction $=68 \%$. Statistical significance level $=1.5 \%$. 
the decadal SST time series are based on averages of years 1-5, 6-10, 11-15, etc. and the decadal MSLP time series are based on averages of years 2-6, 7-11, 12-16, etc.), then the statistical significance level drops to $7.5 \%$. And if the SST domain is extended to also include the extratropical North Atlantic, then the statistical significance level drops further to $1.5 \%$. The SVD heterogeneous correlation patterns and associated time series are shown in fig. 9a,b and fig. 10a,b, respectively.

The SST pattern shows a tripole in the tropical Atlantic. This tripole is also seen in the second mode (not shown) of the SVD analysis of interannually varying SST and MSLP. As the time series and the MSLP correlation pattern for the first interdecadal SVD mode also appear to correspond to those of the second interannual SVD mode (not shown), it seems reasonable to assume that they are in fact the same mode of variability.
The interdecadal SST time series appears to have an oscillation period of around 45 years. Further analysis, including analysis of additional oceanic datasets, is required in order to attempt an explanation of the driving mechanism for this oscillatory behaviour. However, variability in the thermohaline circulation is a possible candidate (Tourre et al., 1999).

A similar analysis of interdecadal covariability for the observational data makes little sense as the available 92 years of data is simply not enough to study variability with expected periods of nearly 50 years.

\section{Interannual predictability}

Seasonal forecasts for surface air temperature and precipitation that are based on statistical relations with tropical SST (e.g., Barnston, 1994)

(a)

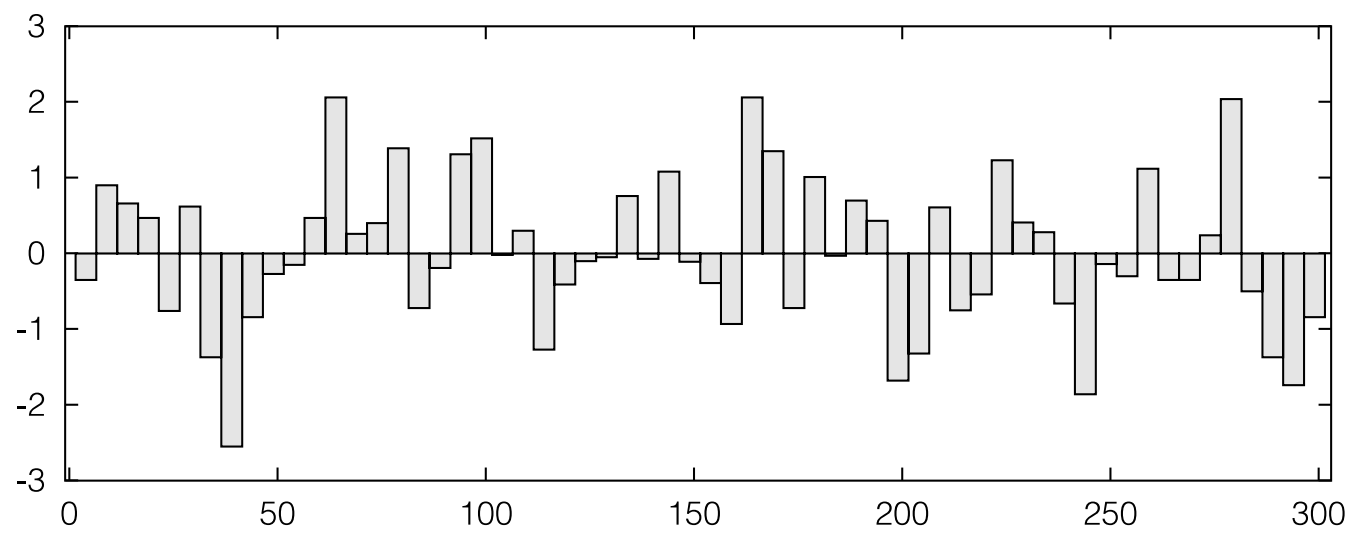

(b)

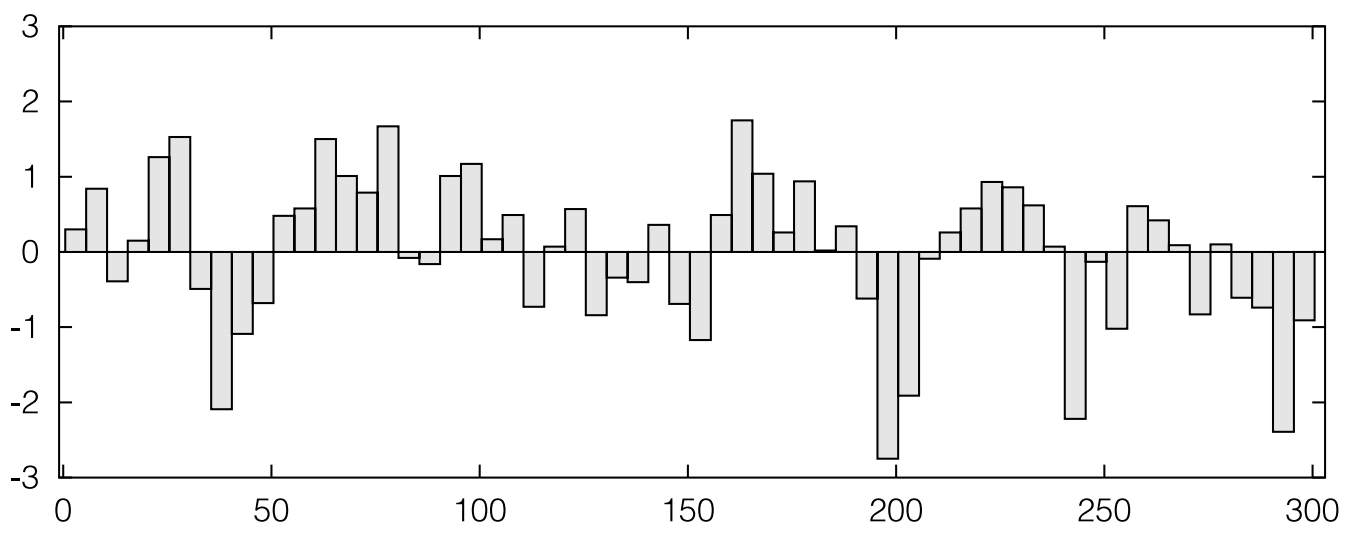

Fig. 10a,b. Standardised time series for the patterns in fig. 9a,b. a) For Atlantic/European MSLP; b) for Atlantic SST. Correlation coefficient between time series is 0.73 . 
are issued routinely around the world (see e.g., The Experimental Long-Lead Forecast Bulletin at http://grads.iges.org/ellfb/). Such statistical forecasts are typically based on records of about 50 years of observational data. In order to estimate forecast skill the statistical predictions are cross-validated, i.e. for each year in the observational record a hindcast is made that is based on a training period that does not include the particular hindcast year (Michaelsen, 1987).

Here the 301-year long model run is used as synthetic data for statistical predictions of an NAO index that describes the large-scale circulation over the Atlantic/European region. The purpose of this exercise is twofold: 1) to quantify predictability of the NAO that can be linearly related to tropical SST; 2) to investigate to what extent the predictive skill depends on (a)

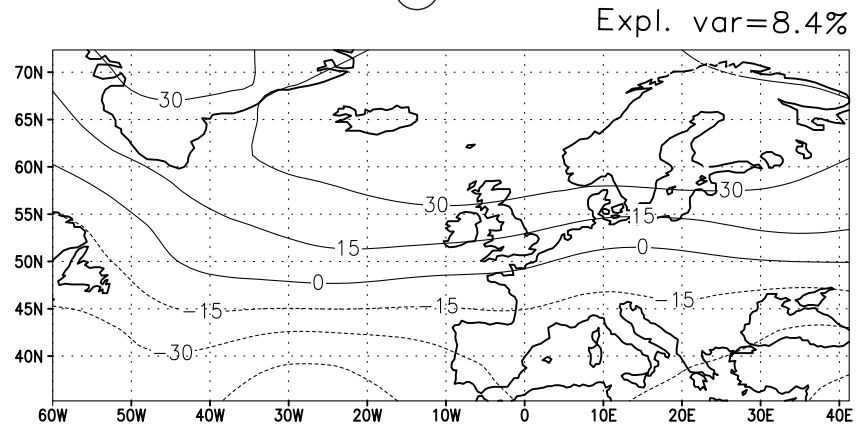

(C)

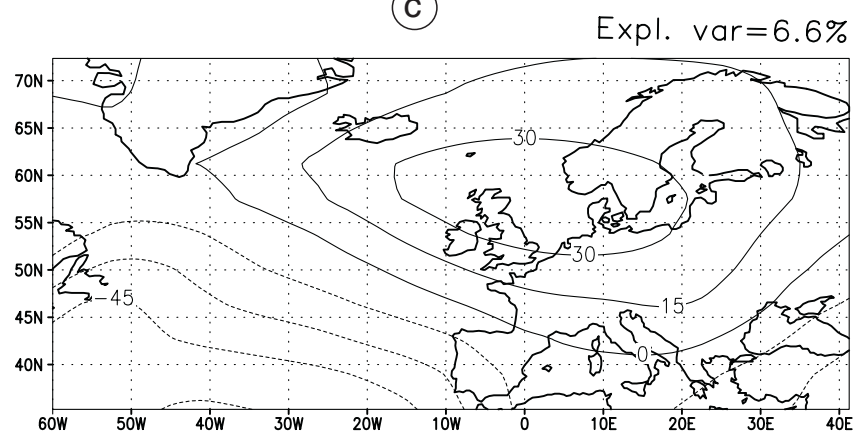

(e)

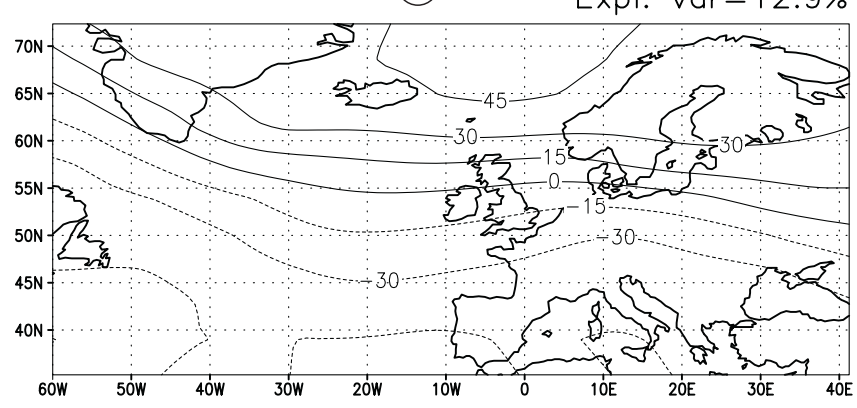

(b)

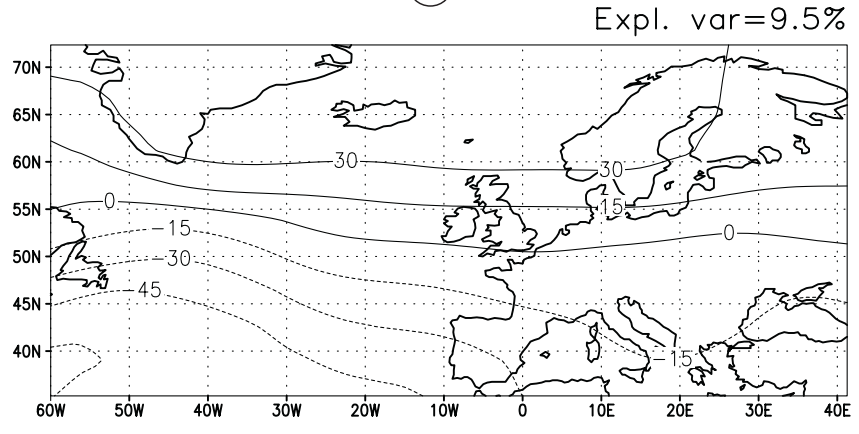

(d)

Expl. $\operatorname{var}=9.3 \%$

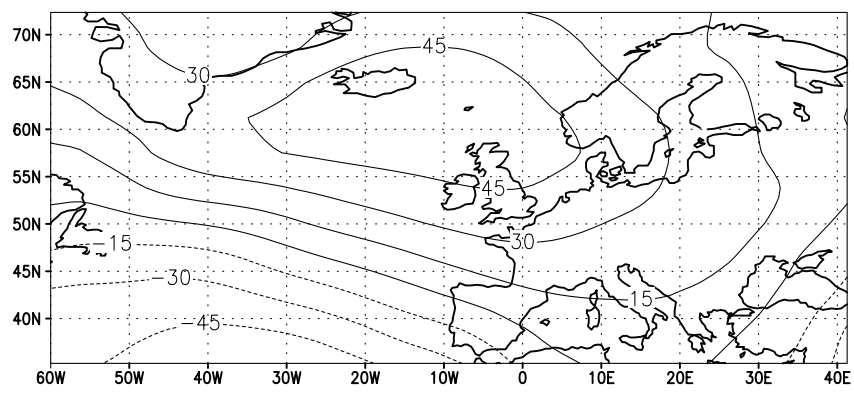

(f)

Expl. var $=13.1 \%$

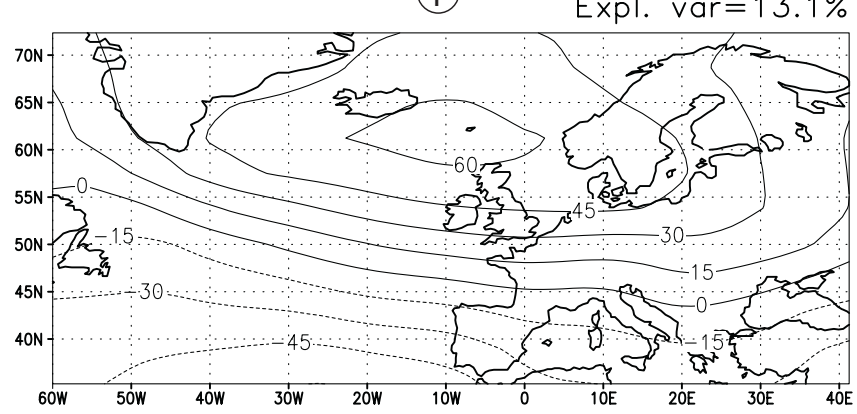

Fig. 11a-f. Leading MSLP heterogeneous correlation patterns from SVD analyses of six different 50-year periods of model simulated JFM seasonal mean tropical SST and JFM seasonal mean Atlantic/European MSLP. a) Years 1-50; b) years 51-100; c) years 101-150; d) years 151-200; e) years 201-250; f) years 251-300. Total explained MSLP variance fractions in the Atlantic/European region vary between $6.6 \%$ and $13.1 \%$. Cf. fig. 5a which is based on an SVD analysis of all 301 model years. 
the length of the statistical training period, and how well the predictive skill is estimated by the cross-validation technique.

The answers to the latter questions require long data series, such as those of the present 301year model run, that are not available for the relatively short record of observational data.

The leading heterogeneous MSLP correlation patterns from SVD analyses of model simulated tropical SST and Atlantic/European MSLP for six non-overlapping 50-year periods show notable differences, although a north/south dipole structure is evident in all six patterns (fig. 11a-f). The fraction of explained interannual MSLP variance in JFM varies between $6.6 \%$ and $13.1 \%$, i.e. by more than a factor 2. SVD analyses of observational data also show differences between the two patterns that are based on the first and the last 46-year period, respectively, of the 19031994 period (fig. 12a,b). These results show that the statistical relationship between tropical SST and Atlantic/European MSLP varies on inter-

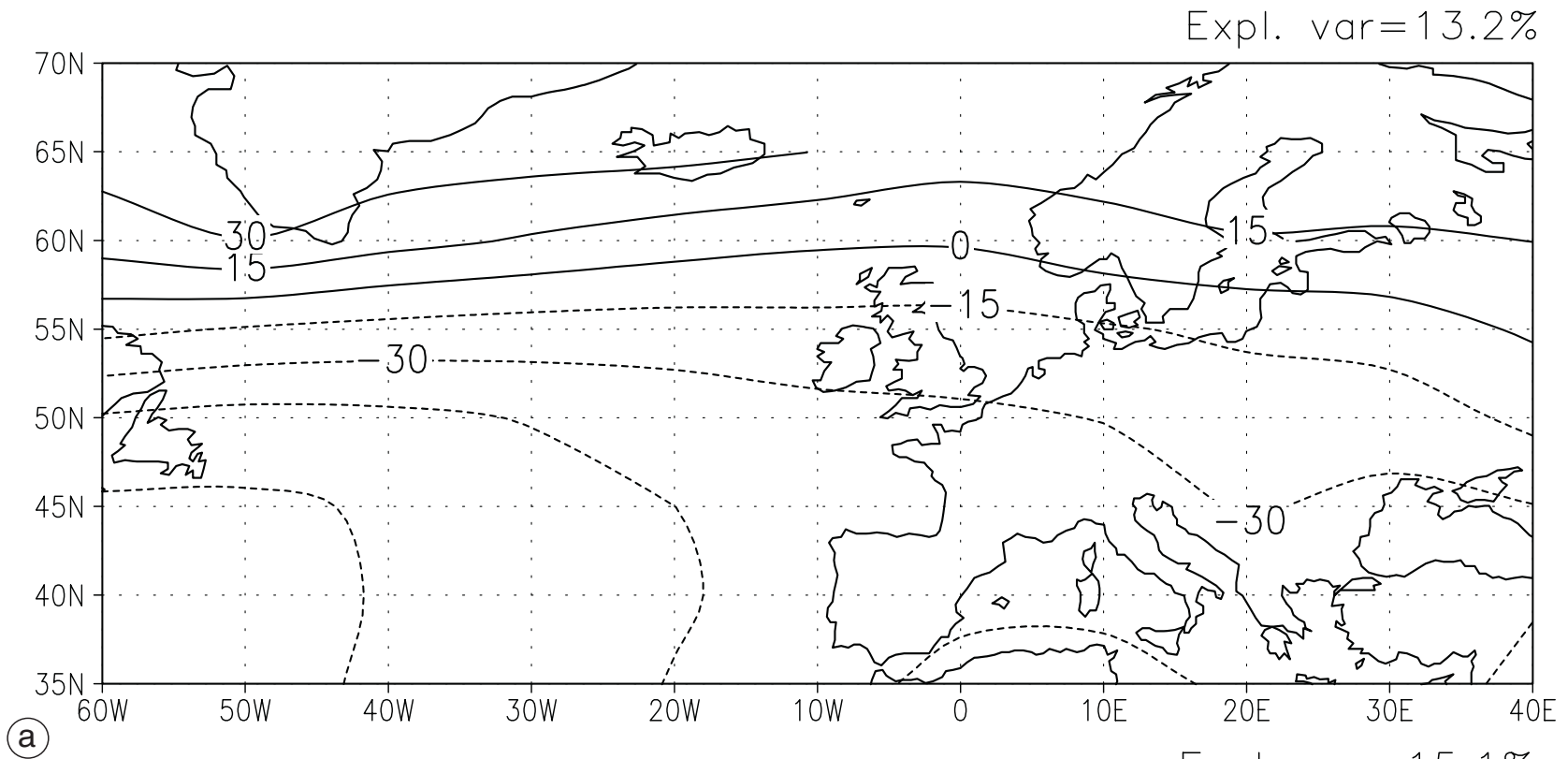

(a)

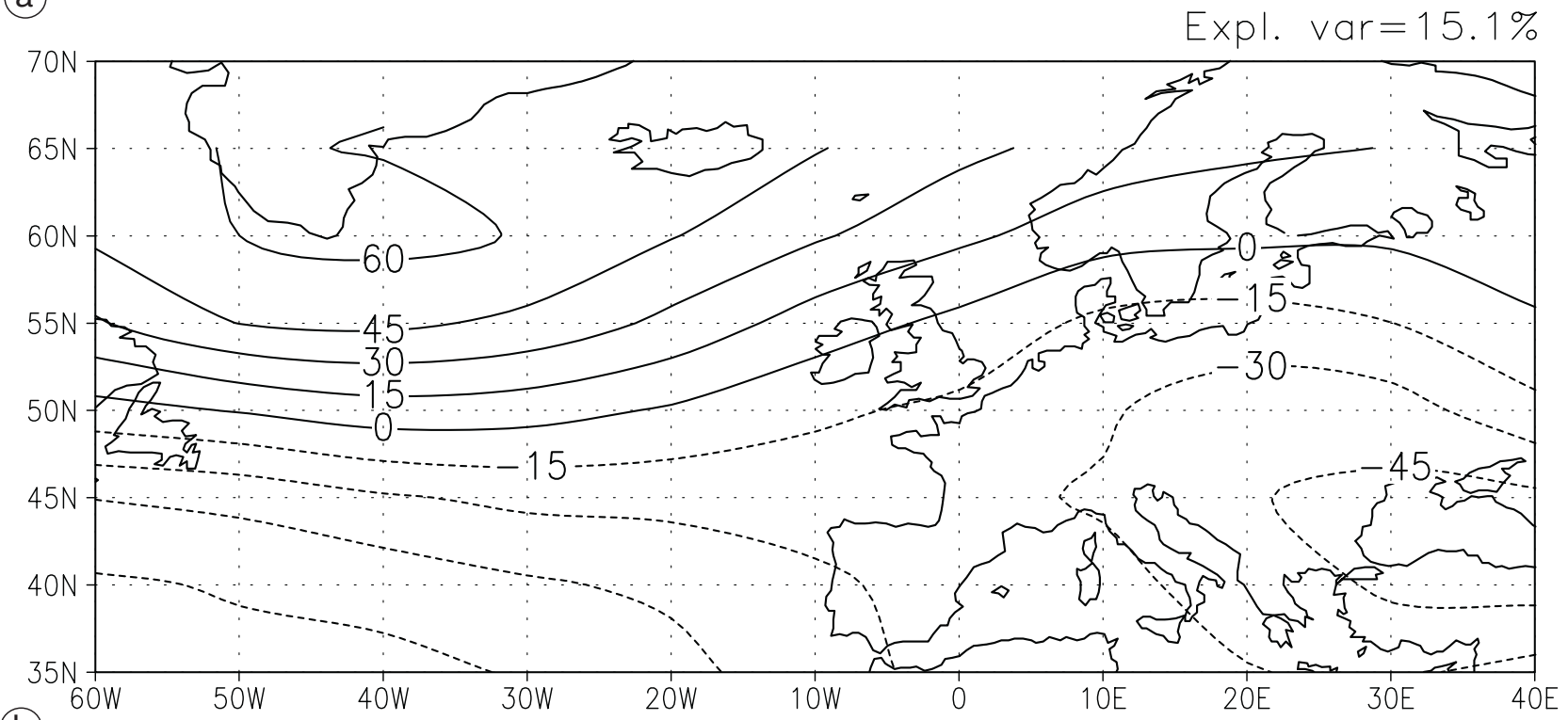

(b)

Fig. 12a,b. Leading MSLP heterogeneous correlation patterns from SVD analyses of two different 46-year periods of gridded observations of JFM seasonal mean tropical SST and JFM seasonal mean Atlantic/European MSLP. a) For 1903-1948; b) for 1949-1994. Cf. fig. 1a which is based on an SVD analysis of all 92 years. 
decadal timescales. Therefore it is likely that interannual predictability of Atlantic/European MSLP will also vary on interdecadal timescales.

Predictions of an NAO index are made by statistical specification of the index (calculated as the difference between MSLP anomalies in the model grid boxes centred approximately at $\left(39^{\circ} \mathrm{N}, 30^{\circ} \mathrm{W}\right)$ and $\left.\left(65^{\circ} \mathrm{N}, 19^{\circ} \mathrm{W}\right)\right)$ from the first three SST time series from an SVD analysis between tropical SST in JFM (or OND) and Atlantic/European MSLP in JFM (that is, for a lead time of zero or one season). The statistical specification is simply made by multiple linear regression of the NAO index on the three SST time series. The choice of including three time series is based on the observation that the squared covariances accounted for by subsequent SVD modes are small, and generally the SCF is tending to zero very slowly for these modes, which would indicate that these modes are close to the «noise level» of the variability (O'Lenic and Livezey, 1988). Moreover, repetition of a few of the predictability calculations described below indicates that including more SST time series in the regression does not lead to an increase of the predictive skill.

First, the predictive skill is calculated as a function of training period length. The validation period is the 150 -year period from year 151 until year 300. A prediction for year $n$ is always based on a training period that ends in year $n-1$, i.e. the training period is sliding through the validation period, just as one would like to always use the latest data for a real statistical forecast. As a measure of predictive skill we use the anomaly correlation. Figure 13 summarises the dependence on training period length for lead times of zero and one season.

For short training periods the predictive skill increases with increasing training period length, but seems to saturate already at training period lengths of about 30 years. This is an encouraging result for statistical seasonal forecasting because it suggests that there is no need for very long training data sets in order to make forecasts for large-scale features such as the NAO index.

The predicted phase of the NAO depends on the phase of ENSO. Figure 14 shows a scatterplot of predicted (at zero lead time and for a 50-year training period) versus actual NAO index in the

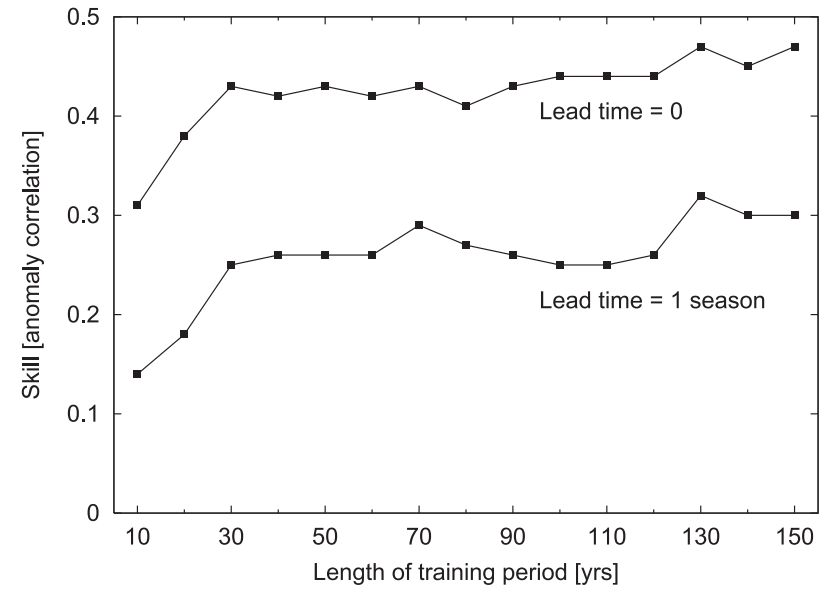

Fig. 13. Predictive skill as function of length of training period for statistical predictions of model simulated NAO index (see text) for JFM, years 151300. Top curve: predictions based on tropical SST from the same season (JFM). Bottom curve: predictions based on tropical SST from the previous season (OND).

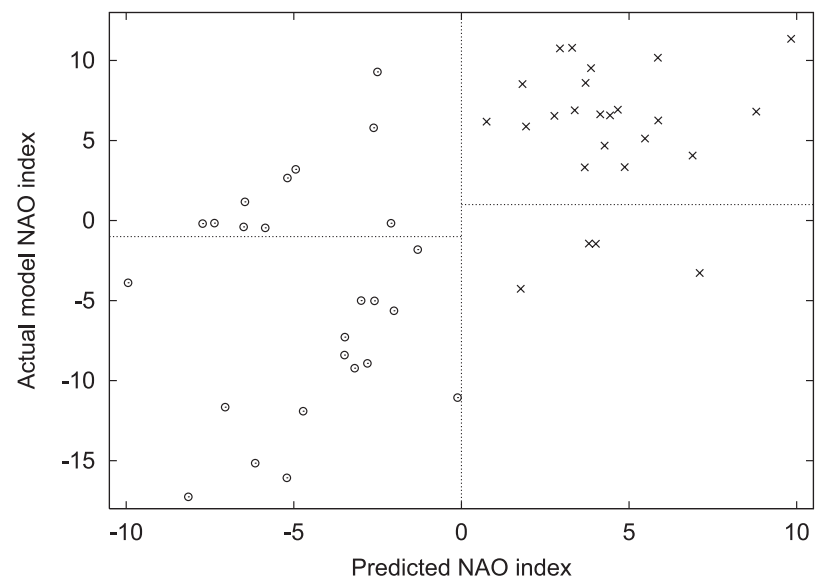

Fig. 14. Actual model NAO index versus statistically predicted NAO index for 25 warm ENSO years (circles) and 25 cold ENSO years (crosses). Lead time $=0$, length of training period $=50$ years. See text for further explanation.

model run for 25 warm and 25 cold ENSO years. Generally, cold ENSO years lead to a positive NAO index, and warm ENSO years lead to a negative NAO index, but the variability of the NAO index is much larger in warm ENSO years than it is in cold ENSO years. Also, a positive NAO index is more likely in a cold ENSO year than a negative NAO index is in a warm ENSO 
year. For example, the NAO index is more than +1 (indicated in fig. 14) in $84 \%$ of the cold ENSO years, whereas the NAO index is less than -1 (indicated in fig. 14) in only $60 \%$ of the warm ENSO years. Thus, it seems that cold ENSO events affect the NAO more than warm ENSO events, as also found in previous studies (Dong et al., 2000; Pozo-Vazquez et al., 2001).

The data from the long model run allows us to compare cross-validated skill scores and skill scores that are estimated from truly independent data. The data is divided into six non-overlapping 50 -year periods. Using each 50 -year period as training period the skill score for prediction of the NAO index is estimated as anomaly correlations for: 1) predictions of the NAO index in the training period itself (i.e. the predicted NAO index is also part of the training data set);2) crossvalidated predictions in the training period (i.e. for each prediction the predicted NAO index is excluded from the training data set), and 3) predictions of the NAO index in the remaining five 50-year periods.

The estimated skill scores are shown in fig. 15a,b. The skill scores that are estimated from dependent data are higher than the cross-validated skill scores in every case, and they are almost always higher than the «true» skill scores for independent data. Overall (i.e. for the average over all cases), the cross-validated skill score matches the «true» skill score very well, but there are individual cases when the cross-validated skill score appears to overestimate the «true» skill score, as well as cases when it appears to under-estimate it.

For both lead times, we find in one of the six cases that one skill score for the independent data falls outside a $95 \%$ confidence interval for the cross-validated skill score. Although the confidence interval is estimated under the assumption that the NAO index follows a normal distribution, the result indicates that statistically significant differences between cross-validated and true skill scores can occur. It is likely that these differences are caused by the interdecadal variability that was illustrated in fig. 11a-f.

Cross-validated and «true» skill scores were also calculated for the observational data. For two non overlapping 46-year periods (and zero lead time) we find skill scores that are comparable to those of the model run as shown fig. 15a.
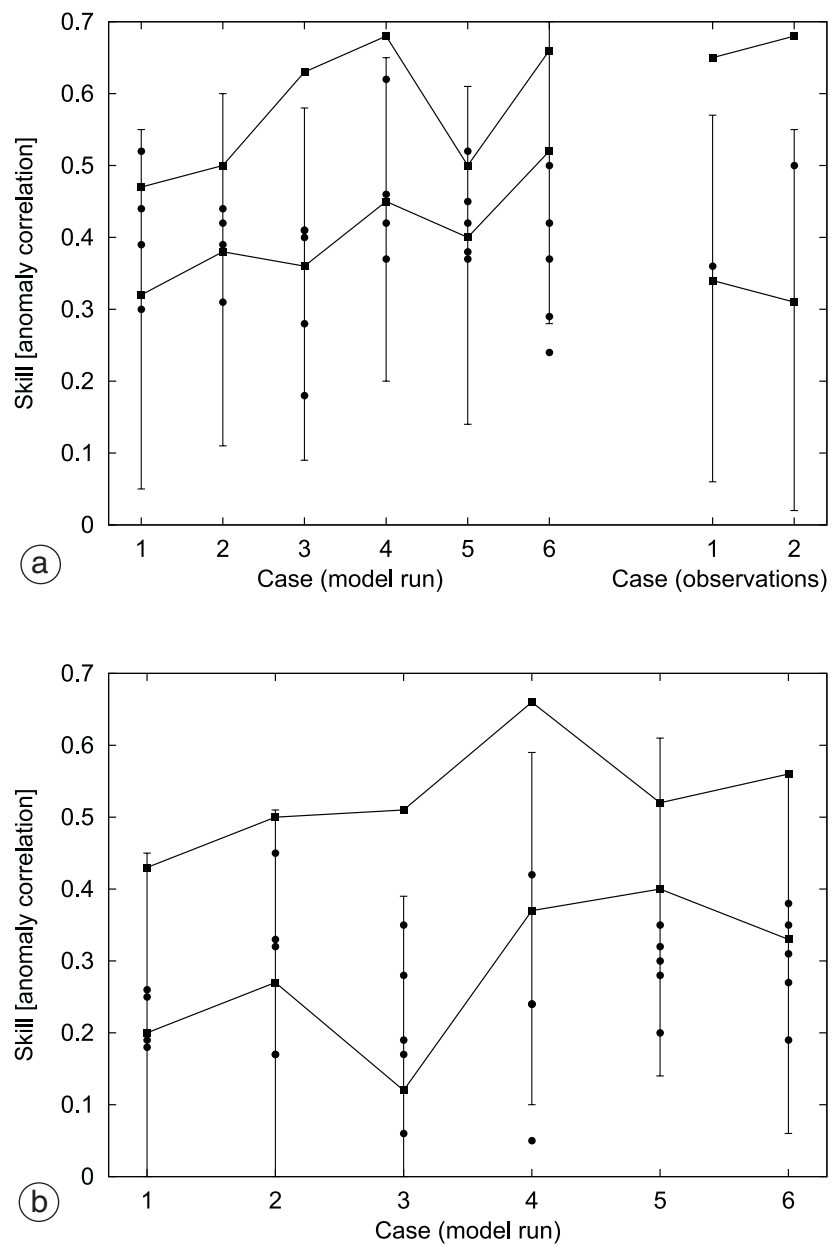

Fig. 15a,b. Predictive skill for statistical predictions of model simulated NAO index in JFM as estimated from six non-overlapping 50-year training periods for the model run (case 1-6). Top curve: validation period identical to training period. Bottom curve: as top curve, but using cross-validation (see text). Error bars: estimated $95 \%$ confidence interval for cross validated skill scores. Circles: validation periods not overlapping with training period. a) Predictions based on tropical SST from JFM, i.e. lead time $=0$. Predictive skill scores are also included for two non-overlapping 46year training periods for gridded observations. b) Predictions based on tropical SST from OND, i.e. lead time $=1$ season.

\section{Conclusions}

It has been demonstrated that the large-scale seasonal mean atmospheric circulation in winter (JFM) in the Atlantic/European region is statistically related to tropical SST. This has been shown for both 92 years of gridded observations of Atlantic/European MSLP and for 301 years 
of coupled ocean/atmosphere model simulations. Although the average effect is small (only about $7 \%$ of the total interannual variance of Atlantic/ European MSLP is explained by the leading mode of interannual variability in tropical SST), it makes sense to take advantage of the existence of this tropical/extratropical teleconnection in seasonal predictions of Atlantic/European climate, particularly in years when there is a strong forcing from tropical SST.

A statistically significant relation between interdecadal variations of Atlantic SST and Atlantic/European MSLP has been found for the 301 years of model simulations. A corresponding pair of patterns have not been identified for the observational data, as only 92 years of observational data were available, which is insufficient to identify an interdecadal mode with a dominant oscillation period of around 45 years.

The statistical relation between tropical SST and Atlantic/European MSLP in winter is sufficiently strong to allow us to make skilful statistical seasonal forecasts of an NAO index, using linear statistical techniques, such as multiple linear regression on the leading SVD modes.

The training period for the statistical forecasts of the NAO index need not be very long in order to obtain good skill scores. Increasing the length of the training period beyond 30 years does not seem to add more skill to the predictions.

Estimation of the expected predictive skill is an important part of seasonal forecasting. Skill estimation is typically done by hindcasting, preferably cross-validated, but it has been demonstrated here that interannual predictability is affected by interdecadal variability. Thus, skill score estimates obtained by cross-validation of statistical hindcasts can be misleading in the presence of interdecadal variability.

\section{Acknowledgements}

This work was supported by the Commission of the European Union through the «Environment and Climate Programme» under contract ENV4CT98-0714, «Interannual to decadal climate variability: scale interaction experiments».

\section{REFERENCES}

BARNSTON, A.G. (1994): Linear statistical short-term climate predictive skill in the Northern Hemisphere, J. Climate, 7, 1513-1564.

BASNETT, T.A. and D.E. PARKER (1997): Development of the global mean sea level pressure data set GMSLP2, Climatic Research Technical Note n. 7, Hadley Centre, Meteorological Office, Bracknell, pp. 16 plus appendices.

Brankovic, C. and T.N. PAlmer (1997): Atmospheric seasonal predictability and estimates of ensemble size, Mon. Weather Rev., 125, 859-874.

Bretherton, C.S., C. SMith and J.M. WALlaCe (1992): An intercomparison of methods for finding coupled patterns in climate data, J. Climate, 5, 541-560.

CHERRY, S. (1996): Singular value decomposition analysis and canonical correlation analysis, J. Climate, 9, 20032009.

DAVIES, J.R., D.P. RowELL and C.K. FolLAND (1997): North Atlantic and European seasonal predictability using an ensemble of multidecadal atmospheric GCM simulations, Int. J. Climatology, 17, 1263-1284.

Dong, B.W., R.T. SuTTON, S.P. JEWSON, A. O’NeILl and J.M. SLINGO (2000): Predictable winter climate in the North Atlantic sector during the 1997-1999 ENSO cycle, Geophys. Res. Lett., 27, 985-988.

FEDDERSEN, H. (2000): Impact of global sea surface temperature on summer and winter temperatures in Europe in a set of seasonal ensemble simulations, $Q$. $J$. R. Meteorol. Soc., 126, 2089-2109.

FRAEDRICH, K. and K. MÜLLER(1992): Climate anomalies in Europe associated with ENSO extremes, Int. J. Climatol., 12, 25-31.

HARRISON, D.E. and N.K. LARKIN (1998): El Niño Southern Oscillation sea surface temperature and wind anomalies, 1946-1993, Rev. Geophys., 36, 353-399.

JohansSon, A., A. BARnston, S. SAHA and H. VAN DEN DoOL (1998): On the level and origin of seasonal forecast skill in Northern Europe, J. Atmos. Sci., 55, 103-127.

JONES, P.D. (1987): The early twentieth century Arctic Highfact or fiction?, Clim. Dyn., 1, 63-75.

LEGUTKE, S. and E. MAIER-REIMER (1999): Climatology of the HOPE-G global ocean general circulation model, DKRZ Technical Report n. 21 (Deutsches Klimarechenzentrum, Hamburg), pp. 50.

MAY, W. and L. BENGTSSON (1998): The signature of ENSO in the Northern Hemisphere midlatitude seasonal mean flow and high-frequency intraseasonal variability, Meteorol. Atmos. Phys., 69, 81-100.

MiCHAELSEN, J. (1987): Cross-validation in statistical climate forecast models, J. Climate Appl. Meteor., 26, 15891600.

O'Lenic, E.A. and R.E. Livezey (1988): Practical considerations in the use of Rotated Principal Component Analysis (RPCA) in diagnostic studies of upper-air height fields, Mon. Weather Rev., 116, 1682-1689.

POZO-VAZQUES, D., M.J. ESTEBAN-PARRA, F.S. RODRIGO and Y. CASTRO-DIEZ (2001): The association between ENSO and winter atmospheric circulation and temperature in the North Atlantic region, J. Climate, 14, 3408-3420. 
RAYNer, N.A., E.B. HorTOn, D.E. PARKER, C.K. Folland and R.B. HACKETT (1996): Version 2.2 of the global seaice and sea surface temperature data set, Climatic Research Technical Note n. 74, Hadley Centre, Meteorological Office, Bracknell, pp. 1903-1994.

Roeckner, E., K. Arpe, L. Bengtsson, M. Christoph, L. DÜMENIL, M. ESCH, M. GiORGETTA, U. SCHLESE and U. SCHULZWEDA (1996): The atmospheric general circulation model ECHAM4: model description and simulation of present-day climate, MPI report $n$. 218, Max Planck Institut für Meteorologie, Hamburg, pp. 90.

Rowell, D.P. (1998): Assessing potential seasonal predictability with an ensemble of multidecadal GCM simulations, J. Climate, 11, 109-120.

STENDEL, M. and E. ROECKNER (1998): Impacts of horizontal resolution on simulated climate statistics in ECHAM4, MPI report n. 253, Max Planck Institut für Meteorologie,
Hamburg, pp. 57.

ThOMPSON, D.W.J. and J.M. WALlaCE (1998): The Arctic Oscillation signature in the wintertime geopotential height and temperature fields, Geophys. Res. Lett., 25, 1297-1300.

TOURRE, Y.M., B. RAJAGOPALAN and Y. KushniR (1999): Dominant patterns of climate variability in the Atlantic Ocean during the last 136 years, J. Climate, 12, 22852299.

Wallace, J.M., C. SMith and C.S. BRETherTon (1992): Singular value decomposition of wintertime sea surface temperature and 500-mb height anomalies, J. Climate, 5, 561-576.

WARD, M.N. and A. NAVARRA (1997): Pattern analysis of SST-forced variability in ensemble GCM simulations: examples over Europe and the tropical Pacific, $J$. Climate, 10, 2210-2220. 